\title{
Article \\ Study on the Mechanism of the Blood-Glucose-Lowering Effect of Collagen Peptides from Sturgeon By-Products
}

\author{
Yukiho Sasaoka ${ }^{1, *(D)}$, Taichi Takagi ${ }^{1}$, Shunta Michiba ${ }^{1}$, Yohei Yamamoto ${ }^{1}$, Yuya Kumagai ${ }^{2}$ (D) \\ and Hideki Kishimura $2, *$ (D)
}

1 Marine Chemical Resource Development, Graduate School of Fisheries Sciences, Hokkaido University, Hakodate, Hokkaido 041-8611, Japan; tkg.taichi@gmail.com (T.T.); shun_ta_soft@yahoo.co.jp (S.M.); bknb626@gmail.com (Y.Y.)

2 Laboratory of Marine Chemical Resource Development, Faculty of Fisheries Sciences, Hokkaido University, Hakodate, Hokkaido 041-8611, Japan; yuyakumagai@fish.hokudai.ac.jp

* Correspondence: sasaoka-yukiho@hro.or.jp (Y.S.); i-dulse@fish.hokudai.ac.jp (H.K.); Tel.: +81-158-23-3266 (Y.S.); +81-138-40-5519 (H.K.)

Citation: Sasaoka, Y.; Takagi, T.;

Michiba, S.; Yamamoto, Y.; Kumagai,

Y.; Kishimura, H. Study on the

Mechanism of the Blood-Glucose-

Lowering Effect of Collagen Peptides from Sturgeon By-Products. Mar.

Drugs 2021, 19, 584. https://doi.org/ $10.3390 / \mathrm{md} 19100584$

Academic Editor: Bill J. Baker

Received: 23 September 2021

Accepted: 15 October 2021

Published: 19 October 2021

Publisher's Note: MDPI stays neutral with regard to jurisdictional claims in published maps and institutional affiliations.

Copyright: (c) 2021 by the authors. Licensee MDPI, Basel, Switzerland. This article is an open access article distributed under the terms and conditions of the Creative Commons Attribution (CC BY) license (https:// creativecommons.org/licenses/by/ $4.0 /)$

\begin{abstract}
In a previous study, we found that the collagen peptides prepared from the by-products of Bester sturgeon had an inhibitory effect on elevated blood glucose levels in a glucose tolerance test with ICR mice. In the present study, we examine the mechanism of the effect of sturgeon collagen peptides (SCPs) in detail. When glucose was orally administered to mice along with the SCPs, it was found that the glucose remained in the stomach for a longer time. In the above tests, the amount of glucose excreted in the feces of mice also increased. On the contrary, it was revealed that the SCPs have a dipeptidyl-peptidase-IV (DPP-IV) inhibitory ability in an in vitro test. In subsequent oral and intravenous glucose administration tests, glucagon-like peptide-1 (GLP-1) and insulin levels in the blood of mice were maintained at high levels. These results suggested the following three mechanisms: SCPs slow the rate of transportation of glucose from the stomach into the small intestine, resulting in delayed glucose absorption; SCPs suppress the absorption of glucose in the small intestine and excrete it from the body; SCPs inhibit DPP-IV in the blood and maintain a high GLP-1 level in blood, which in turn stimulates insulin secretion.
\end{abstract}

Keywords: sturgeon by-products; collagen peptides; blood glucose level; suppression of absorption; DPP-IV; GLP-1; insulin

\section{Introduction}

The number of diabetics in the world is increasing due to cultural and social lifestyle changes associated with economic development. According to a report by the International Diabetes Federation, the total number of diabetic patients in the world was 463 million in 2019, and will rise to 578 million by 2030, and 700 million by 2045 [1]. In addition, it is expected that the number of diabetic patients will reach 628.6 million by 2045 , making the prevention of diabetes an urgent issue [1]. Over $90 \%$ of diabetic patients have type 2 diabetes mellitus, which is closely related to insulin, a glucose metabolism hormone secreted by the pancreas. Insulin is the only hormone that lowers blood glucose levels by causing blood glucose to be taken up by muscle and fat cells. However, genetic factors such as race and ancestry, environmental factors such as overeating, stress, obesity, smoking, and a lack of exercise, and aging factors induce a decrease in insulin secretion from the pancreas and a decrease in the efficiency of glucose uptake by muscles (insulin resistance) [2,3]. In addition, loss of muscle mass due to aging and lack of exercise leads to a decrease in glucose uptake, causing a constant state of hyperglycemia [1,4]. Hyperglycemia damages the heart, blood vessels, eyes, kidneys, and nerves, which may lead to blindness, limb amputation, kidney failure, and death [1,5]. As hypoglycemic agents, glinides and sulfonylureas are commonly used. However, these drugs are used to treat diabetes, not to prevent the onset of diabetes. 
In recent years, to prevent type 2 diabetes, it has been recommended to reduce the intake of sugar, carbohydrates, and fat, and to improve the content of the diet by incorporating vegetables and fruits [4]. For example, the consumption of fish and seaweed has been shown to be associated with a reduced risk of developing type 2 diabetes [6-8]. These food components prevent a progression to type 2 diabetes by stopping a rapid increase in postprandial blood glucose levels and reducing the burden on the pancreas. If postprandial blood glucose levels can be easily controlled with food components, it may be the most effective means of preventing diabetes. In a previous study, we isolated an acid- and heat-stable trypsin inhibitory peptide from the viscera of Japanese common squid (Todarodes pacificus) [9]. We reported that the squid trypsin inhibitor did not inhibit elevated blood glucose in healthy Wistar rats, but only in GK rats that were a model of type 2 diabetes, and its effect was related to an improvement in insulin secretion in GK rats $[9,10]$. It was concluded that the enhanced insulin secretion was due to the fact that the inhibitor reached the small intestine without being digested by proteolytic enzymes and increased the secretion of digestive hormones (gastrin, gastrokine, cholecystokinin) [11].

Sturgeons inhabit a wide range of aquatic areas, including large rivers, such as the Amur (Heilongjiang), Yangtze, and Danube, and lakes and inland seas of the Northern Hemisphere [12,13]. It is one of the largest freshwater fish species, growing up to $8 \mathrm{~m}$ in length and more than $1 \mathrm{t}$ in weight, depending on the species $[12,13]$. They are large-sized and have many edible parts, therefore, they are an important source of protein, especially along the Caspian Sea coast and in Russia [14]. In addition, swim bladders and salted egg products have high economic value as isinglass and caviar, respectively [14,15]. In Japan, sturgeon have been farmed since the 1980s for the purpose of harvesting eggs and meat, while other parts, such as skin, fin, and bone, are by-products that are not fully utilized [16]. However, these parts are rich in collagen [17]. We previously prepared collagen peptides from Bester sturgeon (Huso $\times$ Acipenser ruthenus) by-products (the skin, fin, and bone), and investigated the inhibitory effect of the sturgeon collagen peptides (SCPs) on elevated blood glucose levels [18]. As a result, we found that the SCPs showed an inhibitory effect on elevated blood glucose levels in a glucose tolerance test with ICR mice. We clarified that most of the peptides in the SCPs, fractionated by gel filtration and reversed-phase HPLC, consisted of Gly-X-Y ( $X$ and $Y$ are optional amino acid residues) repetitive sequences, which are common to the triple helical region of the collagen molecules [18]. Therefore, in this study, we further investigated the mechanism of the effect of the SCPs in detail.

\section{Results and Discussion}

\subsection{Effect of the SCPS on $\alpha$-Glucosidase and Invertase Abilities}

Inhibition of $\alpha$-glucosidase in the small intestine by food-derived components is widely known as one of the mechanisms for the suppression of blood glucose elevation.

In this study, we investigated the inhibitory activity of the SCPs on $\alpha$-glucosidase and invertase from rat small intestine. However, the SCPs did not inhibit either enzyme (Figure 1a,b). 

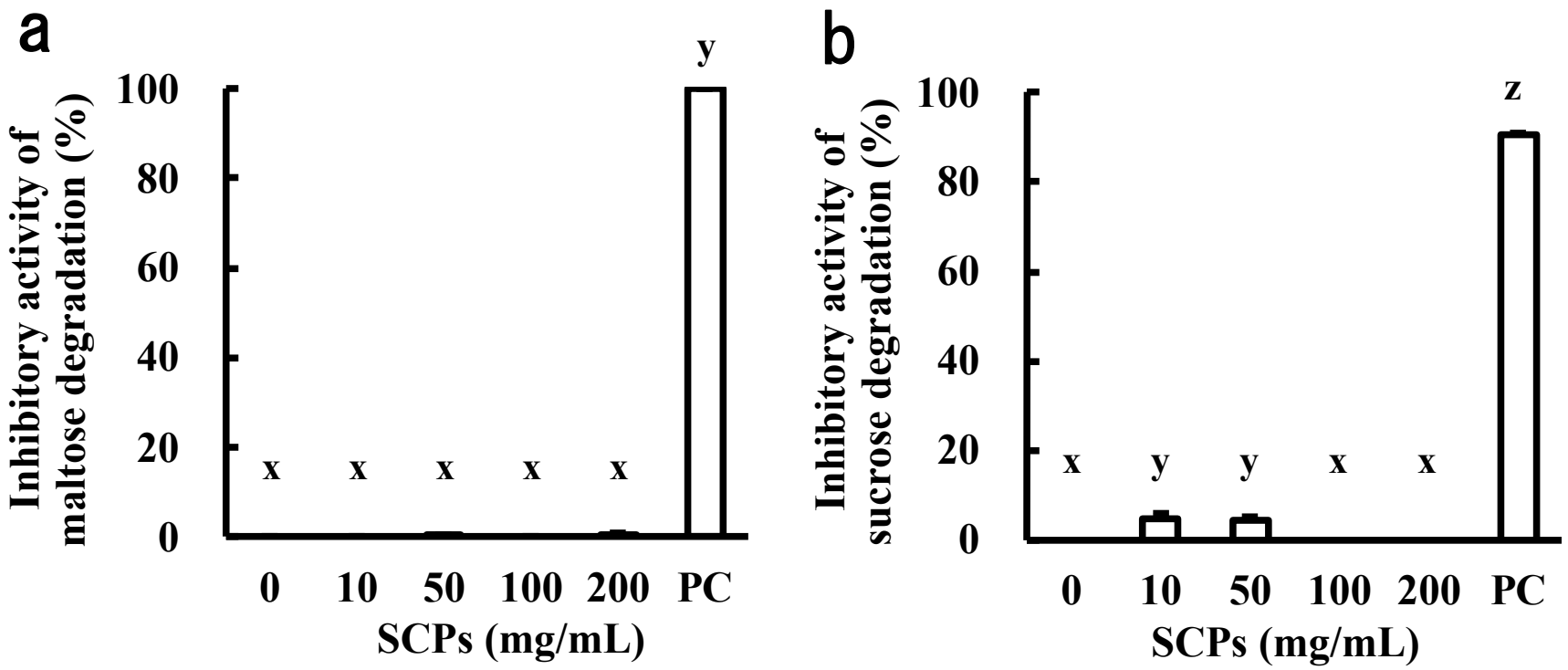

Figure 1. Effect of the SCPs on $\alpha$-glucosidase and invertase abilities. (a) Inhibitory activity of the SCPs on $\alpha$-glucosidase; (b) inhibitory activity of the SCPs on invertase. Bars represent standard errors. There is a significant difference between different signs ( $\mathrm{x}, \mathrm{y}$, and $\mathrm{z})(p<0.05$; Tukey-Kramer test). PC: 1-deoxynojirimycin. Data are expressed as mean $\pm \mathrm{SEM}$ $(n=3-4)$.

2.2. Effect of the Orally Administrated SCPS on Residual Glucose Content in the Stomach in the Oral Glucose Tolerance Test (OGTT)

We hypothesized that prolonged glucose residence time in the stomach would reduce the rate of glucose influx from the stomach to the small intestine and suppress the rapid increase in blood glucose. Therefore, we investigated the effect of the orally administrated SCPs on the residence time of glucose in the stomach. As shown in Figure 2, the glucose existence rates at 15 and 30 min after oral administration in the SCP group (34.6 \pm 1.9 and $17.3 \pm 0.8 \%$, respectively) were significantly higher than those of the control group $(22.7 \pm 3.1$ and $6.6 \pm 2.4 \%$, respectively). To further confirm this result, we carried out an experiment using porcine collagen peptides. The results showed that the amount of glucose remaining in the porcine collagen peptides group was also higher than that of the control group, and the glucose existence rates at $15 \mathrm{~min}(33.8 \pm 1.5 \%)$ were significantly higher than those of the control group (Figure 2). In general, the transfer rate from the stomach to the small intestine slows down with the amounts of solids in the sample $[19,20]$. The soluble solids in the SCP group sample (23.3\%) were higher than those of the control group sample $(13.3 \%)$. In addition to the physical effect, it was reported that when proteins are ingested, the transport of proteins from the stomach to the small intestine is inhibited to allow for adequate protein digestion in the stomach [21]. In other words, it has been reported that collagen peptides upregulate GLP-1 secretion, which delays gastric emptying [22,23]. Therefore, it is possible that the SCPs may also delay gastric emptying indirectly via GLP-1 secretion. For these two reasons, it was thought that the glucose in the SCP group sample remained in the stomach along with the SCPs for a longer time. 


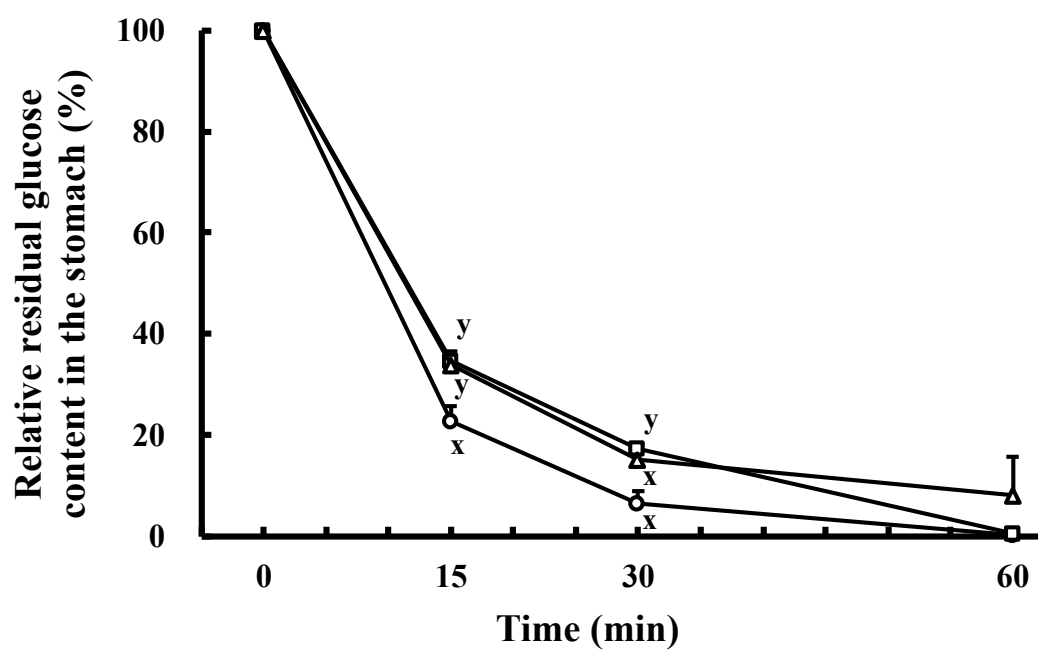

Figure 2. Effect of the SCPs on glucose retention in the stomach in the OGTT in normal mice. Relative residual glucose content in the stomach. Open circles: the control group; open squares: the SCP group; open triangles: the porcine collagen peptides group. Data are expressed as mean \pm SEM ( $n=2$ at $0 \mathrm{~min}, n=3$ at $15 \mathrm{~min}, n=4$ at $30 \mathrm{~min}, n=2$ at $60 \mathrm{~min}$ ). There is a significant difference between different signs ( $\mathrm{x}$ and $\mathrm{y})(p<0.05$; Tukey-Kramer test).

\subsection{Effect of the Orally Administrated SCPs on Glucose Absorption in the Small Intestine in the OGTT}

To investigate the effect of SCPs on glucose absorption in the small intestine, the glucose excretion rate in feces was measured. After passing through the small intestine, carbohydrates are metabolized by intestinal microorganisms in the colon and cecum. In our earlier studies, we examined the amount of glucose excreted in feces using rats, but we were unable to detect glucose in feces (data not shown). Hence, in the present study, we used ICR mice, which have a smaller cecum than rats. The vertical axis in Figure 3 shows the glucose excretion rate in feces when the glucose dose weight $(2.0 \mathrm{~g} / \mathrm{kg}$ body weight $)$ is set to $100 \%$. As a result, $33.2 \mathrm{mg} / \mathrm{g}$ of dry feces $(6.4 \pm 0.1 \%$ of the glucose dose) was detected in the feces in the distilled water group, and $38.6 \mathrm{mg} / \mathrm{g}$ of dry feces $(9.3 \pm 0.1 \%$ of the glucose dose) was detected in the SCP group. The glucose excretion rate of the SCP group was significantly $(p<0.01)$ higher than that of the distilled water group. These results suggested that the orally administered SCPs inhibited glucose absorption in the small intestine, resulting in increased glucose excretion.

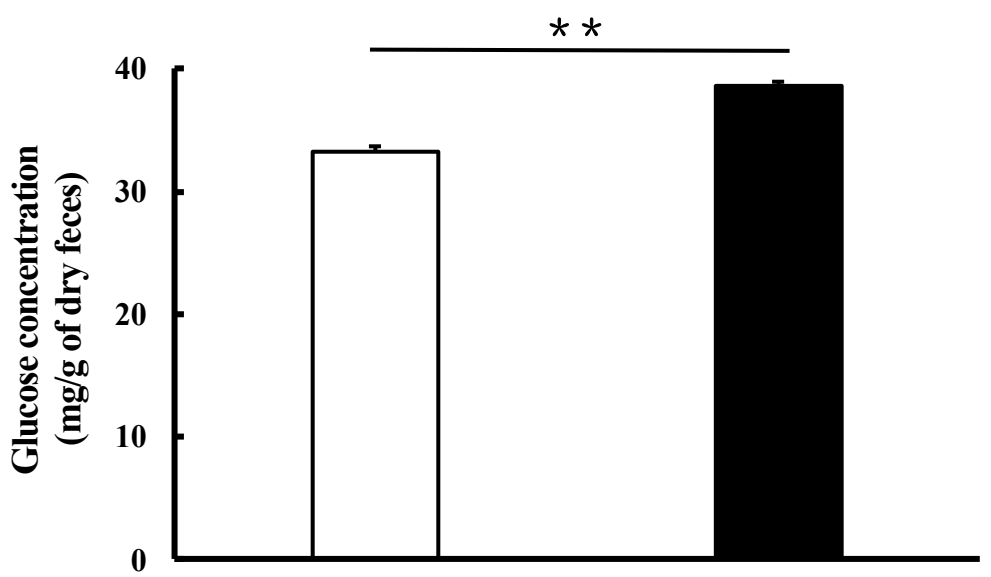

Figure 3. Effect of SCPs on glucose absorption in the small intestine in OGTT in normal mice. The white column: the control group; the black column: the SCP group. Data are expressed as mean \pm SEM $(n=8)$. Values with asterisk indicate statistically significant difference ${ }^{* *} p<0.01$; Student's $t$-test). 


\subsection{Effect of the Orally Administrated SCPs on Blood Glucose and Insulin Levels in the Intraperitoneal Glucose Tolerance Test (IPGTT)}

As mentioned above, it was found that the SCPs suppress the rise in blood glucose level by delaying and inhibiting the absorption in the small intestine in the OGTT. Thus, we measured blood glucose levels when the SCPs and glucose were administered orally and intraperitoneally, respectively. As shown in Figure 4a, in the IPGTT, the blood glucose levels in the SCP group were significantly lower than those of the control groups at 30, 45, 60 , and $120 \mathrm{~min}$. Although, there was no significant difference between the control and the SCP groups in terms of blood glucose levels at $15 \mathrm{~min}$ in the IPGTT, the blood glucose levels of the SCP group were lower than those of the control group after $15 \mathrm{~min}$. The result, that the blood glucose levels of both groups rose similarly between 0 and $15 \mathrm{~min}$ in the IPGTT, indicated that the SCPs may have suppressed the rise in blood glucose level by delaying glucose transportation in the stomach and inhibiting glucose absorption in the small intestine in the OGTT. From the results, we speculated that the SCPs not only delay and inhibit absorption in the small intestine, but also may suppress the increase in blood glucose levels in vivo.
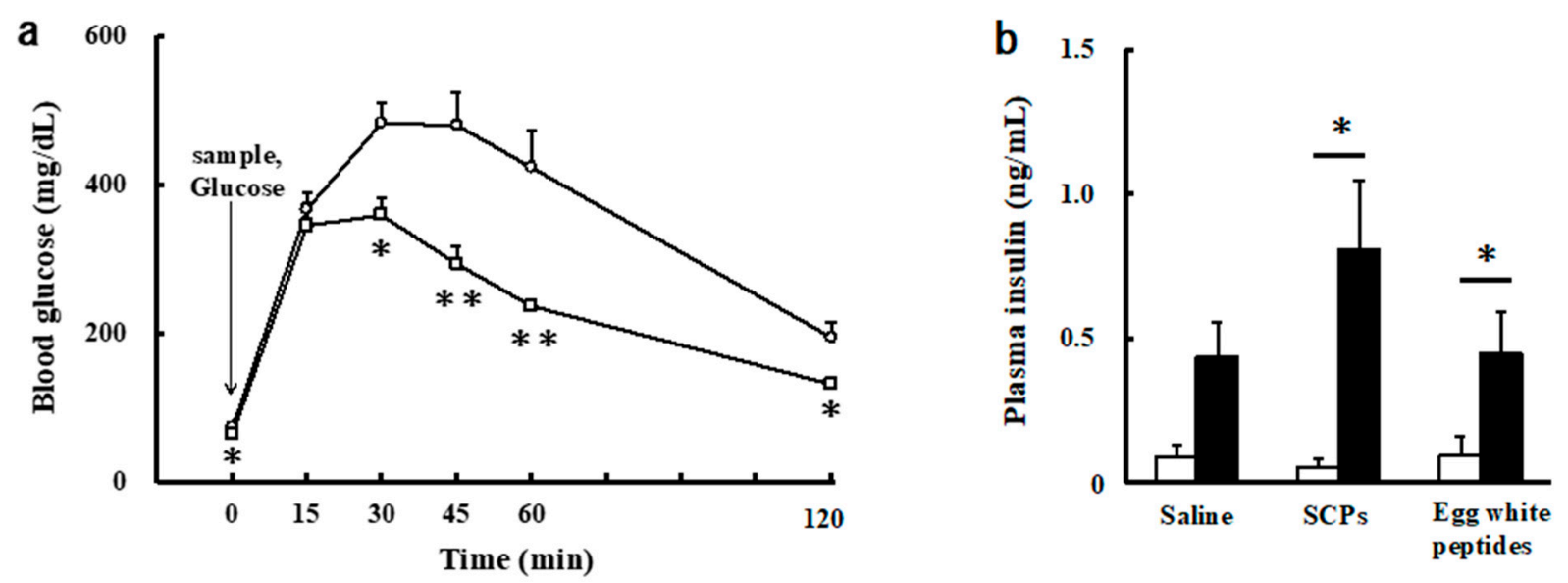

Figure 4. Effect of the orally administrated SCPs on blood glucose and insulin levels in the IPGTT in normal mice. (a) Blood glucose levels when the SCPs and glucose were administered orally and intraperitoneally, respectively. Open circles: the control group; open squares: the SCP group. Data are expressed as mean \pm SEM $(n=7)$. Values at the same time-point with asterisk indicate statistically significant difference $\left({ }^{*} p<0.05,{ }^{* *} p<0.01\right.$; Mann-Whitney $U$ test). (b) Plasma insulin levels when sample (saline, SCPs, egg white peptides) and glucose were administered orally and intraperitoneally, respectively. The white columns: the values at $0 \mathrm{~min}$; the black columns: the values at $15 \mathrm{~min}$. Data are expressed as mean $\pm \mathrm{SEM}$ $(n=5-6)$. Values with asterisk indicate statistically significant difference $(p<0.05$; Wilcoxon rank sum test).

Moreover, we examined the effect of the orally administrated SCPs on blood insulin level in the IPGTT. The insulin level was 4.9 times higher than that of the basal level in the control group, whereas the level was 15.4 times higher than that of the basal level in the SCP group (Figure $4 \mathrm{~b}$ ). Additionally, the insulin level of the SCP group at $15 \mathrm{~min}$ was 1.8 times higher than that of the control group. On the other hand, the insulin level was 4.8 times higher than that of the basal level in the egg white peptide group, and the insulin level of the egg white peptide group at $15 \mathrm{~min}(0.449 \mathrm{mg} / \mathrm{dL})$ was almost the same as that of the control group $(0.439 \mathrm{mg} / \mathrm{dL})$. The results supported the above hypothesis that SCPs suppress the increase in blood glucose levels by insulin secretion, in addition to delaying glucose transportation in the stomach and inhibiting glucose absorption in the small intestine. Furthermore, its insulin secretory promoting effect was more effective than that of egg white peptides. 


\subsection{Effect of the Intravenously Injected SCPs on Blood Glucose and Insulin Levels in the IPGTT}

As described before, it was found that the SCPs have the potential to suppress the increase in blood glucose levels through the secretion of insulin, in addition to delaying glucose transportation in the stomach and inhibiting glucose absorption in the small intestine. In general, gelatin and collagen peptides have resistance to enzymatic degradation $[24,25]$. We further investigated the effect of the intravenously injected SCPs on blood glucose and insulin levels in the IPGTT.

First, before the intravenous injection, we measured the amounts of coexistent endotoxin in the SCP samples that were prepared on different days. As shown in Table 1, both samples had less than $0.1 \mathrm{ng} / \mathrm{mg}$ (SCPs-1: $0.014 \mathrm{ng} / \mathrm{mg}$; SCPs-2: $0.100 \mathrm{ng} / \mathrm{mg}$ ), suggesting that there was little effect of the endotoxin.

Next, we examined the effect of the intravenously injected SCPs on blood glucose and insulin levels in the IPGTT. As indicated in Figure 5a, the blood glucose levels in the SCP group were lower than those of the control group, and the levels at 15 and 30 min were significantly lower than those of the control group. Furthermore, the insulin levels in the SCP group at 15 and 30 min were higher than those of the control group (Figure $5 b$ ). These results suggested that SCPs, or their degradation products, stimulate the secretion of insulin after it is absorbed from the small intestine and transferred to the veins. Concerning absorption of collagen peptides, some reports have indicated that hydroxyproline (Hyp)-containing collagen peptides increase in human plasma and urine after collagen intake [26,27].

Table 1. Endotoxin concentration of SCPs prepared at different dates.

\begin{tabular}{cc}
\hline Lots & Endotoxin Concentrations \\
\hline SCPs-1 & $0.014 \mathrm{ng} / \mathrm{mg}(0.112$ endotoxin unit $/ \mathrm{mg})$ \\
SCPs-2 & $0.100 \mathrm{ng} / \mathrm{mg}(0.800$ endotoxin unit $/ \mathrm{mg})$ \\
\hline
\end{tabular}
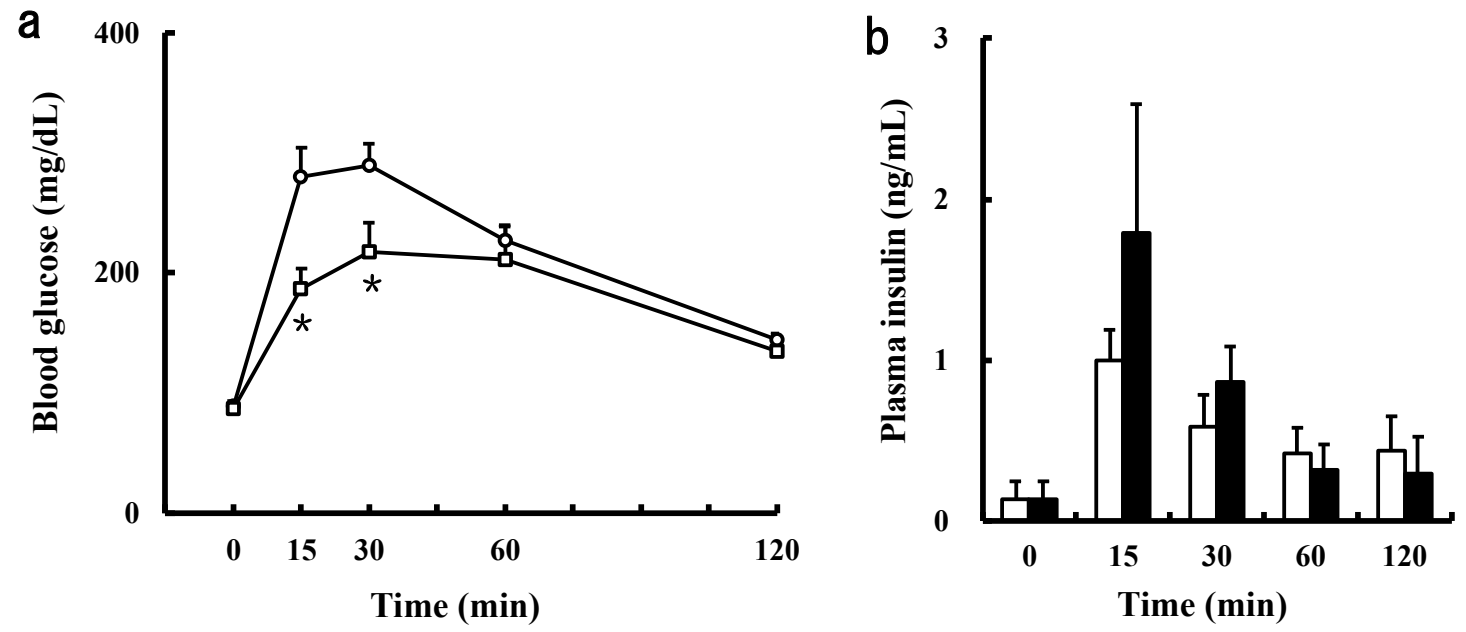

Figure 5. Effect of the intravenously injected SCPs on blood glucose and insulin levels in the IPGTT in normal mice. (a) Blood glucose levels when the SCPs and glucose were injected intravenously and intraperitoneally, respectively. Open circles: the control group; open squares: the SCP group. Data are expressed as mean \pm SEM $(n=6-8)$. Values at the same time-point with asterisk indicate statistically significant difference $\left({ }^{*} p<0.05\right.$; Mann-Whitney $U$ test). (b) Plasma insulin levels when the SCPs and glucose were injected intravenously and intraperitoneally, respectively. The white columns: the control group; the black columns: the SCP group. Data are expressed as mean \pm SEM $(n=3-5)$.

\subsection{Effect of the SCPS on DPP-IV Activity}

Glucagon-like peptide-1 (GLP-1) is synthesized in the L-cells of the small intestine as a glucagon-containing precursor peptide, and is involved in the inhibition of glucagon 
secretion and the promotion of insulin secretion in the pancreas [28]. The N-terminal dipeptides of the GLP-1 are cleaved by DPP-IV (EC 3.4.14.5), and the cleaved GLP-1 acts as an antagonist to the above physiological effects [29]. Therefore, the inhibition of DPP-IV is an effective way to prevent and treat diabetes. DPP-IV is an enzyme that specifically recognizes peptides with a Pro residue (or, to a lesser extent, an Ala residue) at the second position from the $\mathrm{N}$ terminus, and cleaves the $\mathrm{C}$-terminal side of the Pro (or Ala) to release the dipeptide. Li-Chan et al. also reported that a Pro residue was determined as the second $\mathrm{N}$-terminal residue, and was flanked by Gly and Ala in the DPP-IV inhibitory peptides from the skin collagen of Atlantic salmon [30]. In a previous study, we identified several peptides with Pro or Ala residues at the second position from the $\mathrm{N}$ terminus in the SCPs, such as Ala-Ala-Gly-Pro-Hyp-Gly, Gly-Pro-Gly-Gly-Pro-Ala, Gly-Pro-Leu-Gly-Pro-Ala, Ala-Pro-Ala-Gly, and Ala-Pro-Asn-Pro-Phe-Arg-His-Lys [18]. Hence, we predicted that the SCPs would have DPP-IV inhibitory activity. Then, in this study, we investigated the DPPIV inhibitory activity of the SCPs. As a result, we found the SCPs inhibited the formation of the degradation product of $p$-nitroaniline ( $p$-NA) from the substrate (H-Gly-Pro- $p$-NA) by DPP-IV in a concentration-dependent manner, and its $\mathrm{IC}_{50}$ value was $934 \mu \mathrm{g} / \mathrm{mU}$ (Figure 6 , Table 2). Collagen peptides in the previous reports were prepared with enzymes other than papain (Table 2). For example, Flavourzymes and Esperases are mixtures of several enzymes produced by microorganisms, and the peptides prepared by the enzymes are presumed to be composed of different amino acid sequences because of their different cleavage specificities. However, the SCPs showed almost the same inhibitory effect as those of other fish collagen peptides (Table 2). On the other hand, the $\mathrm{IC}_{50}$ of SCPs was higher than those of synthetic peptides (Gly-Pro-Ala-Glu and Gly-Pro-Gly-Ala). SCPs are a mixture of peptides of various sequences and molecular weights. As a result, it was presumed that a large number of peptides with low DPP-IV inhibitory activity were also contained in the SCPs. The average molecular weight of the SCPs was approximately 1400, and many Gly-Pro and Gly-Ala sequences were detected in the internal sequence of the SCPs [18]. Therefore, further hydrolysis of the SCPs would increase the content of peptides with Gly-Pro and Gly-Ala sequences at the $\mathrm{N}$ terminus, which would in turn enhance its DPP-IV inhibitory activity.

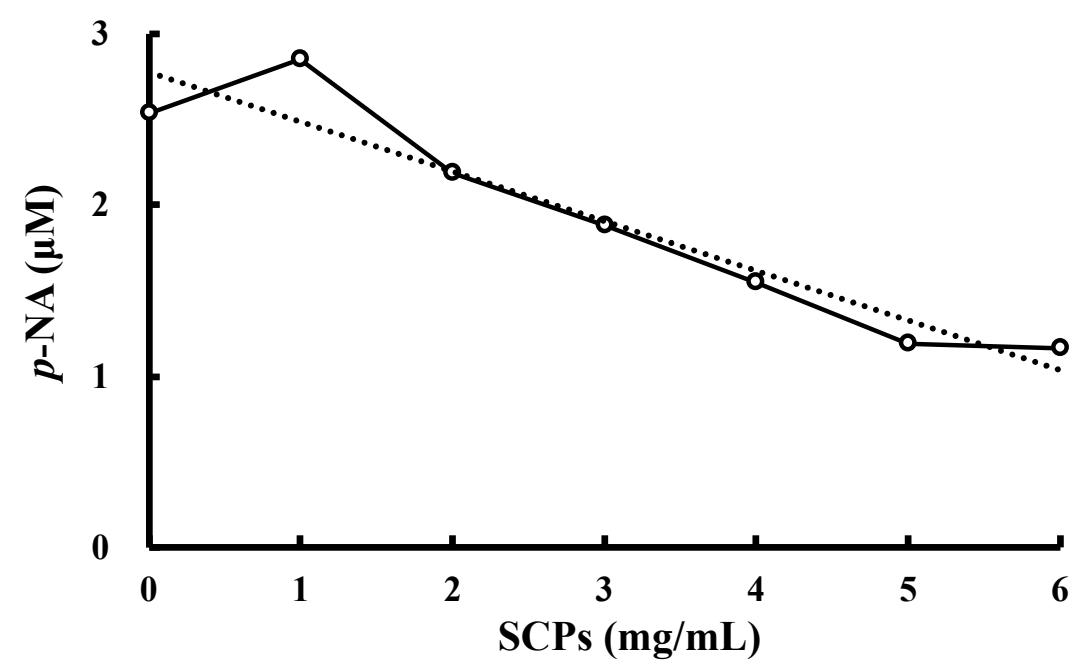

Figure 6. The relationship between the concentrations of the SCPs and the degradation product ( $p$-NA). Error bars are not shown because the SEM is smaller than the height occupied by the symbol representing the mean value $(n=3)$. The dotted line indicates the regression line: $\mathrm{y}=-0.2904 \mathrm{x}+2.78$ $\left(R^{2}=0.9109\right)$. 
Table 2. Characteristics of DPP-VI inhibitory peptides.

\begin{tabular}{|c|c|c|c|c|}
\hline \multirow{2}{*}{ Peptides } & \multirow{2}{*}{$\begin{array}{l}\text { Peptides } \\
\text { MW (Da) }\end{array}$} & \multirow{2}{*}{$\begin{array}{l}\text { Enzymes Used for } \\
\text { Preparation }\end{array}$} & \multicolumn{2}{|c|}{$\mathrm{IC}_{50}$ Values } \\
\hline & & & $(\mu \mathrm{g} / \mathrm{mU})$ & $(\mu \mathrm{mol} / \mathrm{mU})$ \\
\hline SCPs & $1400[18]$ & Papain & 934 & 0.667 \\
\hline $\begin{array}{l}\text { Collagen peptides } \\
\text { (Atlantic salmon skin) [30] }\end{array}$ & $<1000$ & Flavourzyme & 270 & 0.270 \\
\hline Gly-Pro-Ala-Glu [30] & 372.4 & (Synthetic peptide) & 0.924 & $0.248 \times 10^{-2}$ \\
\hline Gly-Pro-Gly-Ala [30] & 300.4 & (Synthetic peptide) & 1.26 & $0.210 \times 10^{-2}$ \\
\hline \multirow[t]{4}{*}{$\begin{array}{l}\text { Collagen peptides } \\
\text { (tilapia scale) [22] }\end{array}$} & - & - & 616 & - \\
\hline & 2935 & Esperase & 425 & 0.145 \\
\hline & 2322 & Savinase & 521 & 0.224 \\
\hline & 1995 & Alcalase & 504 & 0.253 \\
\hline \multirow{5}{*}{$\begin{array}{l}\text { Collagen peptides } \\
\text { (carp skin) [31] }\end{array}$} & 3925 & Trypsin & 479 & 0.122 \\
\hline & 5797 & Izyme G & 714 & 0.123 \\
\hline & 2325 & Protamex & 467 & 0.201 \\
\hline & 7878 & Neutrase & 529 & 0.067 \\
\hline & 15,053 & Peptidase & 527 & 0.035 \\
\hline
\end{tabular}

\subsection{Effect of the Intravenously Injected SCPS on Blood Glucose and GLP-1 Levels in the IPGTT}

As described above, it was found that the SCPs are capable of inhibiting DPP-IV. Since the SCPs delay gastric emptying, as indicated in the previous paragraph, we speculated that the effect of GLP-1 might be superior to that of GIP [32]. Hence, we investigated the effect of the intravenously injected SCPs on blood GLP-1 levels in the IPGTT. As shown in Figure 7a, the blood glucose levels in the SCP group were lower than those of the control group, and the levels at 15,30, and 60 min were significantly lower than those of the control group. Moreover, the GLP-1 levels in the SCP group at 15 and 30 min were maintained higher than those in the control group (Figure $7 \mathrm{~b}$ ). The L-cells, which are located between the duodenum and ileum, are directly and indirectly sensed by food-derived ingredients and their digested products, followed by secreting the GLP-1 [32-34]. Therefore, it was suggested that the SCPs stimulate the secretion of GLP-1 from L-cells, followed by the GLP-1 stimulating the secretion of insulin, resulting in a decrease in blood glucose level. Iba et al. reported that CP increases the level of active GLP-1 [22]. We also found that SCPs increased blood insulin levels, and that SCPs showed DPP-IV inhibitory activity in vitro. Based on these facts, we speculated that SCPs enhance the secretion of GLP-1, which in turn increases the level of active GLP-1, which is not degraded by DPP-IV.

To confirm the above deduction, we tested the temporal changes in blood glucose levels of type 1 diabetic model rats (STZ rats) after intravenous administration of the SCPs and intraperitoneal glucose loading. The SCPs did not lower the blood glucose levels in rats without insulin secretory capacity (Figure 8). It was also reported that the hydrolysates prepared from the skin collagens of Atlantic salmon and porcine prevent the degradation of GLP-1 by DPP-IV, thereby maintaining high blood levels of GLP-1, which in turn promote insulin secretion and improve postprandial hyperglycemia $[22,35,36]$. 

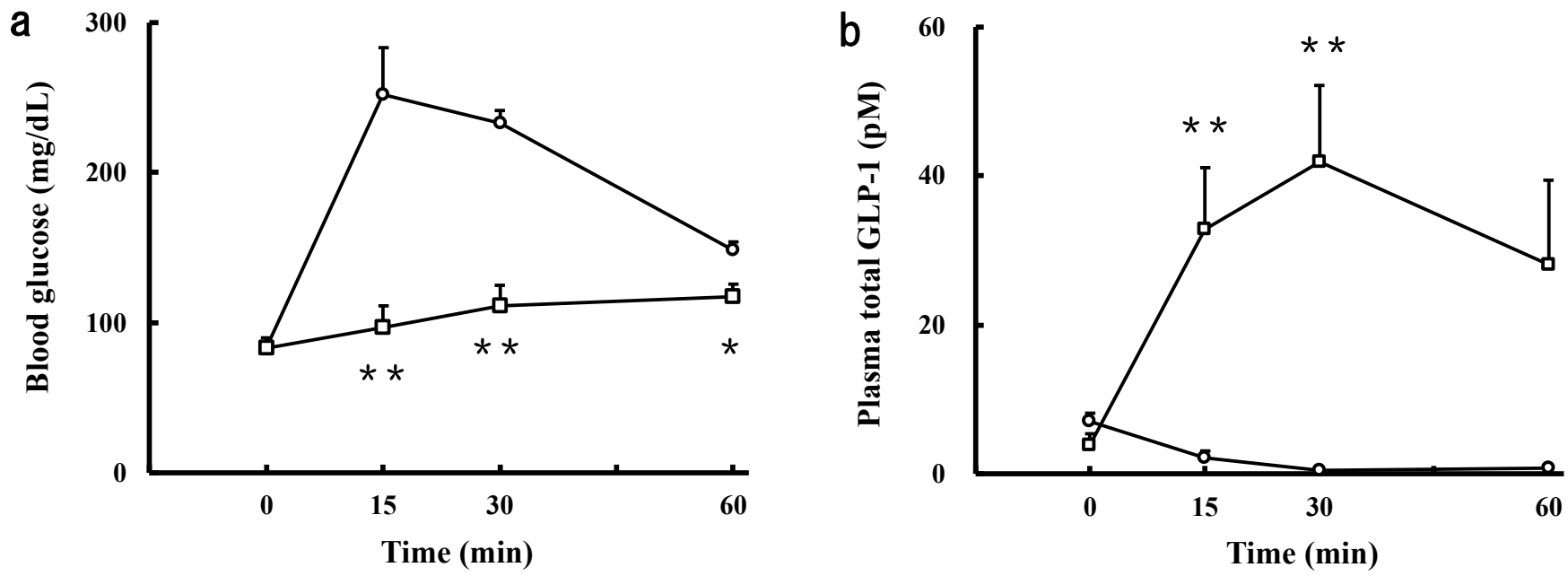

Figure 7. Effect of the intravenously injected SCPs on blood glucose and GLP-1 levels in the IPGTT in normal rats. (a) Blood glucose levels when the SCPs and glucose were injected intravenously and intraperitoneally, respectively. Open circles: the control group; open squares: the SCP group. Data are expressed as mean \pm SEM $(n=6)$. Values at the same time-point with asterisk indicate a statistically significant difference $\left({ }^{*} p<0.05 ;{ }^{* *} p<0.01\right.$; Student's $t$-test). (b) Plasma GLP-1 levels when the SCPs and glucose were injected intravenously and intraperitoneally, respectively. Open circles: the control group; open squares: the SCP group. Data are expressed as mean \pm SEM $(n=6)$. Values at the same time-point with asterisk indicate a statistically significant difference $(* * p<0.01$; Mann-Whitney $U$ test).

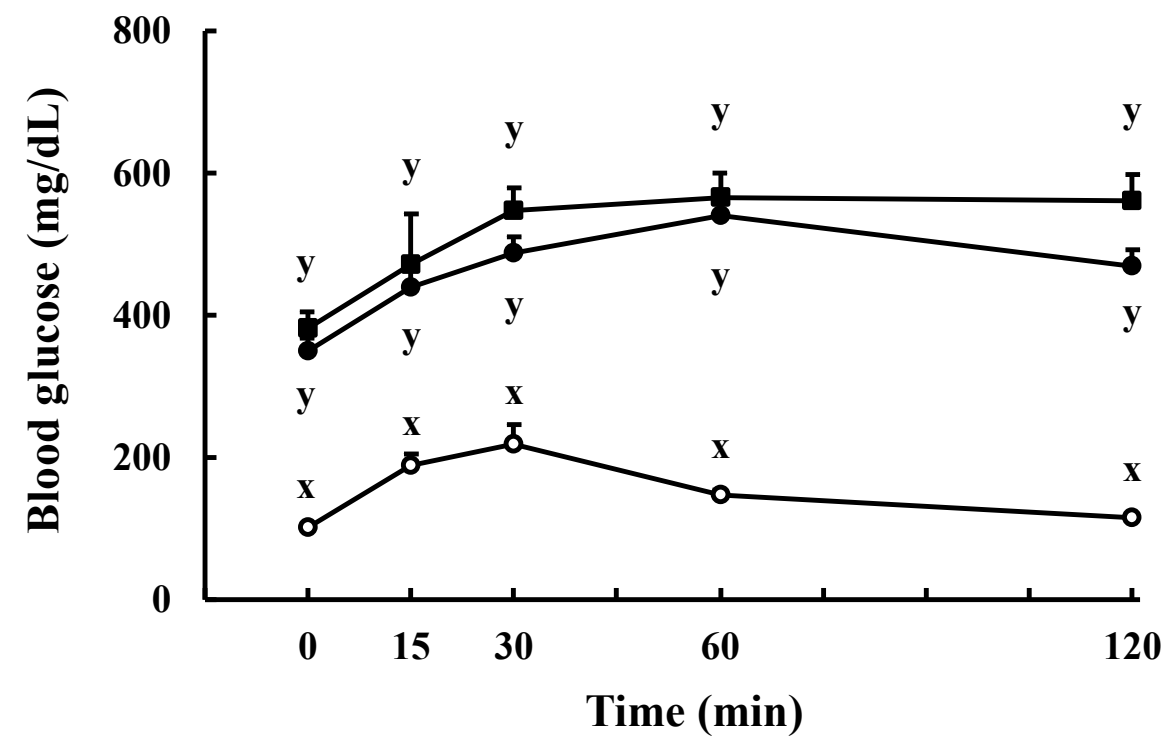

Figure 8. Effect of the intravenously injected SCPs on blood glucose levels of STZ rats in the IPGTT. Open circles: the control group using SD rats; closed circles: the control group using STZ rats; closed squares: the SCP group using STZ rats. Data are expressed as mean $\pm \operatorname{SEM}(n=3-4)$. There is a significant difference between different signs ( $\mathrm{x}$ and $\mathrm{y})(p<0.05$; Tukey-Kramer test).

\section{Materials and Methods}

\subsection{Materials}

Heparin sodium, 1-deoxynojirimycin, aprotinin from bovine lung, streptozotocin, and Glucose CII-Test Wako were purchased from the FUJIFILM Wako Pure Chemical Corporation (Osaka, Japan). Papain (EC 3.4.22.2, 1:350) and porcine-skin-derived gelatin were purchased from Sigma-Aldrich Co. LLC (St. Louis, MO, USA) and the FUJIFILM Wako Pure Chemical Corporation (Osaka, Japan). An LBIS Mouse Insulin ELISA Kit (AKRIN-011T) was purchased from the FUJIFILM Wako Shibayagi Corporation (Gunma, Japan). A Multi Species GLP-1 Total ELISA kit (EZGLP1T-36K) was purchased from Merck 
Millipore (Burlington, MA, USA). Saline was purchased from Otsuka Pharmaceutical Co., Ltd. (Tokyo, Japan). Ethylenediamine- $N, N, N^{\prime}, N^{\prime}$-tetraacetic acid, tripotassium salt, and dihydrate (EDTA 3K) were purchased from Dojindo (Kumamoto, Japan). A DPP-IV Drug Discovery Kit (BML-AK499) was purchased from Enzo Life Sciences, Inc. (Farmingdale, NY, USA). An Endospecy ${ }^{\circledR}$ ES-24S Kit was purchased from the Seikagaku Corporation (Tokyo, Japan). Six-week-old male ICR mice and SD rats were purchased from Charles River Laboratories (Yokohama, Japan). They were maintained under controlled temperature $\left(23 \pm 1{ }^{\circ} \mathrm{C}\right)$, humidity $(50 \pm 10 \%)$, and $12 \mathrm{~h}$-light/dark cycle (light: 08:00-20:00), with free access to deionized water and standard chow (MF diet, Oriental Yeast Co., Tokyo, Japan). All procedures for the use and care of the mice were approved by Institutional Animal Care and Use Committee of National University Corporation Hokkaido University.

The SCPs were prepared as previously described [18]. The skin, fin and bone were harvested from Bester sturgeon and pretreated by soaking in $1 \% \mathrm{NaCl}$ for $48 \mathrm{~h}$ and $0.2 \mathrm{M}$ $\mathrm{NaOH}, 0.2 \mathrm{M} \mathrm{HCl}$, and distilled water for $24 \mathrm{~h}$ in series. Then, the pretreated materials were hydrolyzed by $0.2 \mathrm{wt} \%$ of papain to the SCP at $50{ }^{\circ} \mathrm{C}$ for $5 \mathrm{~h}$. After centrifugation at $4{ }^{\circ} \mathrm{C}$, $10,000 \times g$ for $10 \mathrm{~min}$, the supernatant was lyophilized. Then, lipids in the hydrolysates were removed by soaking in $99.5 \%$ ethanol for $3 \mathrm{~h}$, and delipidated materials were dried by incubation at $60^{\circ} \mathrm{C}$ into the SCPs.

Porcine collagen peptides were prepared from the porcine skin-derived gelatins by the following method. The porcine gelatins were dissolved by adding 20 times $(v / w)$ the volume of distilled water and hydrolyzed by $0.2 \mathrm{wt} \%$ papain to the porcine gelatins at $50{ }^{\circ} \mathrm{C}$ for $5 \mathrm{~h}$. After centrifugation at $4{ }^{\circ} \mathrm{C}, 10,000 \times \mathrm{g}$ for $10 \mathrm{~min}$, the supernatant was lyophilized. Then, lipids in the hydrolysates were removed by soaking in $99.5 \%$ ethanol for $3 \mathrm{~h}$, and delipidated materials were dried by incubation at $60^{\circ} \mathrm{C}$ into the porcine collagen peptides.

Egg white peptides were prepared from commercially available eggs by the following method. The egg whites were dissolved by adding twice the volume $(v / w)$ of distilled water and hydrolyzed by $0.2 \mathrm{wt} \%$ papain to the egg whites collected from hens at $50{ }^{\circ} \mathrm{C}$ for $5 \mathrm{~h}$. After centrifugation at $4{ }^{\circ} \mathrm{C}, 10,000 \times \mathrm{g}$ for $10 \mathrm{~min}$, the supernatant was lyophilized. Then, lipids in the hydrolysates were removed by soaking in $99.5 \%$ ethanol for $3 \mathrm{~h}$, and delipidated materials were dried by incubation at $60{ }^{\circ} \mathrm{C}$ into the egg white peptides.

\section{2. $\alpha$-Glucosidase and Invertase Inhibitory Assays}

Glucose quantitative chromogenic reagents were prepared by dissolving $5.3 \mathrm{mM} 4$ aminoantipyrine, $5.3 \mathrm{mM}$ phenol, 2900 units (U) of glucose oxidase, and $355 \mathrm{U}$ of peroxidase

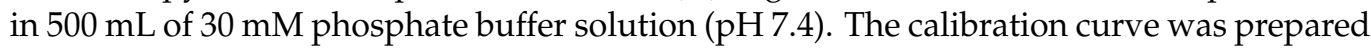
by adding $20 \mu \mathrm{L}$ of glucose solution (final concentration $0-500 \mathrm{mg} / \mathrm{dL}$ ) to $3.0 \mathrm{~mL}$ of the chromogenic reagent, incubating at $37^{\circ} \mathrm{C}$ for $30 \mathrm{~min}$, and then measuring the absorbance at $505 \mathrm{~nm}$. The curve was prepared for each lot of the chromogenic reagent.

The acetone powder $(10 \mathrm{~g})$, prepared from SD rat small intestine, was suspended in $0.1 \mathrm{M}$ maleic acid buffer ( $\mathrm{pH} 6.0$ ) and sonicated. The supernatant was then centrifuged at $5{ }^{\circ} \mathrm{C}$, $1007 \times g$ for $30 \mathrm{~min}$. The supernatant obtained was used as crude $\alpha$-glucosidase-invertase.

The $\alpha$-glucosidase and invertase inhibitory activities were measured according to the method of Ohta et al. [37]. Seventy microliters of $0.1 \mathrm{M}$ maleate buffer (pH 6.0), $10 \mu \mathrm{L}$ of $500 \mathrm{mM}$ maltose or sucrose solution, and $10 \mu \mathrm{L}$ of the SCPs solution (final concentration at $0,10,50,100$, and $200 \mathrm{mg} / \mathrm{mL}$ ) were mixed in vitro. To the mixed solution, $10 \mu \mathrm{L}$ of the crude enzyme was added and incubated at $37^{\circ} \mathrm{C}$ for $60 \mathrm{~min}$ to degrade maltose or sucrose, respectively. After incubation, the enzymatic reaction was stopped by adding $100 \mu \mathrm{L}$ of 2.0 M maleic acid-Tris-NaOH buffer ( $\mathrm{pH}$ 7.4), and the weight of glucose produced was determined by adding $3.0 \mathrm{~mL}$ of glucose quantification chromogenic reagent to $20 \mu \mathrm{L}$ of the reacted solution. The inhibition rate for maltose and sucrose degradation was calculated using the following equation:

$$
\text { inhibitory activity }(\%)=[1-(\mathrm{As}-\mathrm{Asb}) /(\mathrm{Ac}-\mathrm{Acb})] \times 100
$$


where As is the absorbance of the sample, Asb is the absorbance when the stop solution was added to the sample before the reaction, Ac is the absorbance of the buffer, and Acb is the absorbance when the stop solution was added to the buffer before the reaction.

\subsection{DPP-IV Inhibitory Assay}

DPP-IV inhibitory activity of the SCP solution (final concentration at 0, 1, 2, 3, 4, 5 , and $6 \mathrm{mg} / \mathrm{mL}$ ) was measured with the DPP-IV Drug Discovery Kit. One unit (U) of DPP-IV activity was defined as the amount of enzyme causing an increase of $2.09 \times 10^{-2}$ in absorbance at $405 \mathrm{~nm} / \mathrm{min}$, based on the pre-measured results and using distilled water instead of the SCP solution. The $\mathrm{IC}_{50}$ was defined as an SCP concentration that inhibited $50 \%$ of $1 \mathrm{mU}$ DPP-IV.

\subsection{Measurement of Blood Glucose in OGTT}

The OGTT was performed in accordance with the previous study [18]. Briefly, ICR mice or SD rats were divided into a control group and sample groups and fasted for $16 \mathrm{~h}$. After basal blood collection ( $0 \mathrm{~min})$, glucose solution $(2 \mathrm{~g} / \mathrm{kg}$ body weight, $15 \mathrm{~mL} / \mathrm{kg}$ body weight) mixed with distilled water or with sample $(1.5 \mathrm{~g} / \mathrm{kg}$ body weight $)$ were orally injected with a disposable probe (FUCHIGAMI, Kyoto, Japan). A single drop of blood was periodically sampled from the tail vein and glucose levels were measured using a glucose sensor (ACCU-CHEK ST meter, Roche DC Japan K.K., Tokyo, Japan).

\subsection{Measurement of Glucose in the Stomach in OGTT}

ICR mice were divided into a control group and an SCP group matched for body weight and fasted for $16 \mathrm{~h}$. After being orally injected $(0 \mathrm{~min})$, the mice were sacrificed with $\mathrm{CO}_{2}$ gas and the stomachs were immediately extirpated with clamping distal ends of esophagus and pylorus. The stomachs were incised and flushed inside with $1 \mathrm{~mL}$ saline three times. Each stomach's contents and the lavage fluids were mixed and centrifuged at $4{ }^{\circ} \mathrm{C}, 448 \times g$ for $10 \mathrm{~min}$. The supernatants $(20 \mu \mathrm{L})$ were mixed with $3.0 \mathrm{~mL}$ of the coloring reagent. After $30 \mathrm{~min}$ incubation at $37^{\circ} \mathrm{C}$, the absorbance at $505 \mathrm{~nm}$ was measured. Relative residual glucose content in the stomach:

$$
(\%)=\mathrm{S} / \mathrm{C} \times 100
$$

where $S$ is the glucose content in the stomach $(\mathrm{g})$ and $\mathrm{C}$ is the dose of glucose $(\mathrm{g})$.

\subsection{Measurement of Glucose Content in Excrements in OGTT}

ICR mice were divided into a control group and an SCP group matched for body weight and fasted for $16 \mathrm{~h}$. Glucose solution mixed with sample or with distilled water was orally injected, and then the mice were fasted for $24 \mathrm{~h}$. The mice could freely drink exchanged water throughout the test. The excrements that were excreted for $24 \mathrm{~h}$ after the oral administration were collected and lyophilized. After drying, the excrements were grinded and mixed with distilled water. Glucose in the mixtures was extracted by sonication at $20^{\circ} \mathrm{C}$, for $5 \mathrm{~min}$. The extracts were centrifuged at $4{ }^{\circ} \mathrm{C}, 448 \times g$ for $10 \mathrm{~min}$. The glucose concentration of the supernatants was measured as described in Section 2.4. Relative glucose content in the excrements:

$$
(\%)=S / C \times 100
$$

where $S$ is the glucose content in the excrements $(\mathrm{g})$ and $\mathrm{C}$ is the dose of glucose $(\mathrm{g})$.

\subsection{Measurement of Blood Glucose and Insulin Levels in IPGTT}

\subsubsection{Oral Administration of the SCPs}

ICR mice were divided into a control group and an SCP group matched for body weight and fasted for $16 \mathrm{~h}$. After basal blood collection $(0 \mathrm{~min})$, distilled water (control group) or SCP solution $(0.3 \mathrm{~g} / \mathrm{mL}, 1.5 \mathrm{~g} / \mathrm{kg}$ body weight, $10 \mathrm{~mL} / \mathrm{kg}$ body weight) (the SCP 
group) was orally administered with a disposable probe, and glucose solution $(0.4 \mathrm{~g} / \mathrm{mL}$ saline, $2.0 \mathrm{~g} / \mathrm{kg}$ body weight, $5 \mathrm{~mL} / \mathrm{kg}$ body weight) was injected intraperitoneally. A single drop of blood was periodically sampled $(15,30,45,60$, and $120 \mathrm{~min}$ after the glucose injection).

\subsubsection{Intravenous Injection of the SCPs}

ICR mice were divided into a control group and an SCP group matched for body weight and fasted for $16 \mathrm{~h}$. After basal blood collection ( $0 \mathrm{~min}$ ), saline (control group) or SCP solution $(0.3 \mathrm{~g} / \mathrm{mL}$ saline, $1.5 \mathrm{~g} / \mathrm{kg}$ body weight, $5 \mathrm{~mL} / \mathrm{kg}$ body weight) (the SCP group) was intravenously injected into the tail vein with a syringe, and glucose solution $(0.4 \mathrm{~g} / \mathrm{mL}$ saline, $2.0 \mathrm{~g} / \mathrm{kg}$ body weight, $5 \mathrm{~mL} / \mathrm{kg}$ body weight) was injected intraperitoneally. A single drop of blood was periodically sampled $(15,30,60$, and $120 \mathrm{~min}$ after the glucose injection).

\subsection{Measurement of Insulin Levels}

Blood samples $(50 \mu \mathrm{L})$ were periodically drawn into a hematocrit tube coated with heparin (NRIS Micro hematocrit tubes Na-heparinized, $80 \mathrm{IU} / \mathrm{mL}$ ), and poured into a tube containing aprotinin (final concentration at $500 \mathrm{KIU} / \mathrm{mL}$ ) and heparin sodium (final concentration at $50 \mathrm{IU} / \mathrm{mL}$ ). The blood samples were centrifuged at $4{ }^{\circ} \mathrm{C}, 2500 \times g$ for $10 \mathrm{~min}$, and the plasmas were frozen at $-80{ }^{\circ} \mathrm{C}$ until insulin measurement was taken. Plasma insulin levels were measured with LBIS Mouse Insulin ELISA Kit (AKRIN-011T, FUJIFILM Wako Shibayagi Corporation, Gunma, Japan).

In the SCP intravenous injection test, we collected whole blood from individual mice sacrificed periodically at each time point $(0,15,30,60$, and $120 \mathrm{~min}$ after glucose injection) with a syringe containing heparin aprotinin and heparin sodium.

\subsection{Measurement of Total GLP-1 Levels}

Blood samples $(125 \mu \mathrm{L})$ were drawn into a hematocrit tube coated with heparin at 0 and $15 \mathrm{~min}$, and poured into a tube coated with EDTA 3K (final concentration at $1735 \mathrm{mg} / \mathrm{mL}$ ) and heparin sodium (final concentration at $50 \mathrm{IU} / \mathrm{mL}$ ). The blood samples were centrifuged at $4{ }^{\circ} \mathrm{C}, 2500 \times \mathrm{g}$ for $10 \mathrm{~min}$, and the plasmas were frozen at $-80^{\circ} \mathrm{C}$ until an insulin measurement was taken. Total GLP-1 levels in plasma were measured with a Multi Species GLP-1 Total ELISA kit (EZGLP1T-36K, Merck Millipore, Burlington, MA, USA).

\subsection{Measurement of Endotoxin Concentration}

The SCPs was dissolved in distilled water (endotoxin and $\beta$-glucan free) (Seikagaku Corporation, Tokyo, Japan) to a final concentration at $10 \mathrm{mg} / \mathrm{mL}$. Endotoxin concentration was measured with an Endospecy ${ }^{\circledR}$ ES-24S Kit. The potency of control standard endotoxin was 8 endotoxin units (EU)/ng from the certificate of analysis sheet.

\subsection{Preparation of Type 1 Diabetes Model Rats}

$\mathrm{SD}$ rats were divided into a control group and experimental groups matched for body weight. After basal collection under full feeding, saline $(1 \mathrm{~mL})$ (control group) or streptozotocin solution $(1 \mathrm{~mL})(70 \mathrm{mg} / \mathrm{kg}$ body weight, dissolved in $1 \mathrm{~mL}$ of saline) was intraperitoneally injected. After 4 days, blood glucose level under full feeding was measured, and rats with a level over $200 \mathrm{mg} / \mathrm{dL}$ were selected as type 1 diabetes model rats (STZ rats).

\subsection{Statistical Analysis}

The data in this study are expressed as mean \pm standard error of the mean (SEM). Statistical analyses were performed as follows: using the Student's $t$-test, the Mann-Whitney $U$ test, and the Wilcoxon rank sum test. The significance test between the control group and the test group was the Student's $t$-test. The significance test between the control group 
and multiple test groups, and between each test group, was the Tukey-Kramer test. All statistics were completed with Statcel-The Useful Add-in Forms on Excel, 3rd edition (OMS Publishing Inc., Tokorozawa, Japan).

\section{Conclusions}

We previously found that the SCPs prepared from the by-products of Bester sturgeon had an inhibitory effect on elevated blood glucose levels in the OGTT in mice. In this study, we investigated the mechanism of the SCP effect in detail. Consequently, (1) the SCPs did not inhibit $\alpha$-glucosidase and invertase activities in an in vitro test, (2) the SCPs kept the glucose in the stomach longer in the OGTT, (3) the SCPs increased glucose excretion in the OGTT, (4) the orally administrated SCPs lowered the blood glucose level and stimulated the secretion of insulin in the IPGTT, (5) the intravenously injected SCPs lowered the blood glucose level and stimulated the secretion of insulin in the IPGTT, (6) the SCPs inhibited DPP-IV activity in an in vitro test, (7) the intravenously injected SCPs lowered the blood glucose level and maintained higher GLP-1 levels in the IPGTT, (8) the SCPs did not lower the blood glucose levels in rats without insulin secretory capacity (STZ rats). These results suggested that the following three mechanisms have an inhibitory effect on blood glucose caused by the SCPs: the SCPs slow the transportation rate of glucose from the stomach into the small intestine, resulting in delayed glucose absorption; the SCPs suppress the absorption of glucose in the small intestine and excrete it from the body; the SCPs inhibit DPP-IV in the blood and maintain a high GLP-1 level in the blood, which in turn stimulates insulin secretion.

Author Contributions: Conceptualization, Y.S. and H.K.; methodology and validation, Y.S., Y.K. and H.K.; formal analysis, T.T., S.M. and Y.Y.; investigation, Y.S. and H.K.; writing-original draft preparation, Y.S.; writing-review and editing, Y.K. and H.K.; supervision, H.K.; funding acquisition, Y.S. All authors have read and agreed to the published version of the manuscript.

Funding: This research received no external funding.

Institutional Review Board Statement: All procedures for the use and care of the mice were approved by Institutional Animal Care and Use Committee of National University Corporation Hokkaido University (Approval numbers: 10-0032 and 15-0054).

Acknowledgments: The authors would like to thank Shinji Adachi and Yasuaki Takagi for providing the samples.

Conflicts of Interest: The authors declare no conflict of interest.

\section{References}

1. Saeedi, P.; Petersohn, I.; Salpea, P.; Malanda, B.; Karuranga, S.; Unwin, N.; Colagiuri, S.; Guariguata, L.; Motala, A.A.; Ogurtsova, K.; et al. Global and regional diabetes prevalence estimates for 2019 and projections for 2030 and 2045: Results from the International Diabetes Federation Diabetes Atlas, 9th edition. Diabetes Res. Clin. Pract. 2019, 157, 107843. [CrossRef] [PubMed]

2. Kieffer, T.J.; McIntosh, C.H.; Pederson, R.A. Degradation of glucose-dependent insulinotropic polypeptide and truncated glu-cagon-like peptide 1 in vitro and in vivo by dipeptidyl peptidase IV. Endocrinology 1995, 136, 3585-3596. [CrossRef] [PubMed]

3. Tanaka, M.; Masuda, S.; Yamakage, H.; Inoue, T.; Ohue-Kitano, R.; Yokota, S.; Kusakabe, T.; Wada, H.; Sanada, K.; Ishii, K.; et al. Role of serum myostatin in the association between hyperinsulinemia and muscle atrophy in Japanese obese patients. Diabetes Res. Clin. Pract. 2018, 142, 195-202. [CrossRef] [PubMed]

4. Shannon, E.; Abu-Ghannam, N. Seaweeds as nutraceuticals for health and nutrition. Phycologia 2019, 58, 563-577. [CrossRef]

5. World Health Organization. Fact Sheet: Diabetes. Available online: https://www.who.int/news-room/fact-sheets/detail/ diabetes (accessed on 7 October 2021).

6. Hirata, Y.; Nomura, K.; Senga, Y.; Okada, Y.; Kobayashi, K.; Okamoto, S.; Minokoshi, Y.; Imamura, M.; Takeda, S.; Hosooka, T.; et al. Hyperglycemia induces skeletal muscle atrophy via a WWP1/KLF15 axis. JCI Insight 2019, 4, e124952. [CrossRef] [PubMed]

7. Nanri, A.; Mizoue, T.; Noda, M.; Takahashi, Y.; Matsushita, Y.; Poudel-Tandukar, K.; Kato, M.; Oba, S.; Inoue, M.; Tsugane, S.; et al. Fish intake and type 2 diabetes in Japanese men and women: The Japan Public Health Center-based Pro-spective Study. Am. J. Clin. Nutr. 2011, 94, 884-891. [CrossRef]

8. Liaset, B.; Øyen, J.; Jacques, H.; Kristiansen, K.; Madsen, L. Seafood intake and the development of obesity, insulin resistance and type 2 diabetes. Nutr. Res. Rev. 2019, 32, 146-167. [CrossRef] 
9. Kishimura, H.; Nagai, Y.; Fukumorita, K.; Adachi, K.; Chiba, S.; Nakajima, S.; Saeki, H.; Klomklao, S.; Nalinanon, S.; Benjakul, S.; et al. Acid- and heat-stable trypsin inhibitory peptide from the viscera of japanese common squid (Todarodes pacificus). J. Food Biochem. 2010, 34, 748-763. [CrossRef]

10. Kishimura, H.; Fukumorita, K.; Adachi, K.; Chiba, S.; Nagai, Y.; Katayama, S.; Nakajima, S.; Saeki, H. A trypsin inhibitor in the viscera of japanese common squid (Todarodes pacificus) elicits insulinotropic effects in diabetic GK rats hypoglycemic effects of squid viscera. J. Food Biochem. 2012, 36, 93-98. [CrossRef]

11. Adachi, K.; Fukumorita, K.; Araki, M.; Zaima, N.; Yang, Z.-H.; Chiba, S.; Kishimura, H.; Saeki, H. Transcriptome Analysis of the Duodenum, Pancreas, Liver, and Muscle from Diabetic Goto-Kakizaki Rats Fed a Trypsin Inhibitor Derived from Squid Viscera. J. Agric. Food Chem. 2012, 60, 5540-5546. [CrossRef]

12. Billard, R.; Lecointre, G. Biology and conservation of sturgeon and paddlefish. Rev. Fish Biol. Fish. 2000, 10, 355-392. [CrossRef]

13. WWF. Saving Sturgeons-A Grobal Report on Their Status and Suggested Conservation Strategy; WWF: Gland, Switzerland, 2016; pp. 2-3.

14. Bronzi, P.; Chebanov, M.; Michaels, J.T.; Wei, Q.; Rosenthal, H.; Gessner, J. Sturgeon meat and caviar production: Global update. J. Appl. Ichthyol. 2019, 35, 257-266. [CrossRef]

15. Bronzi, P.; Rosenthal, H.; Gessner, J. Grobal sturgeon aquaculture production: An overview. J. Appl. Ichthyol. 2011, 27, 169-175. [CrossRef]

16. Takahashi, S. Sturgeon conservation and the role of Japan. In The State of Wildlife Trade in Japan; Ishihara, A., Traffic East Asia-Japan, Eds.; TRAFFIC East Asia-Japan: Tokyo, Japan, 2010; pp. 42-47.

17. Zhang, X.; Ookawa, M.; Tan, Y.; Ura, K.; Adachi, S.; Takagi, Y. Biochemical characterisation and assessment of fibril-forming ability of collagens extracted from Bester sturgeon Huso huso $\times$ Acipenser ruthenus. Food Chem. 2014, 160, 305-312. [CrossRef] [PubMed]

18. Sasaoka, Y.; Kishimura, H.; Adachi, S.; Takagi, Y. Collagen peptides derived from the triple helical region of sturgeon collagen improve glucose tolerance in normal mice. J. Food Biochem. 2017, 42, e12478. [CrossRef]

19. Dooley, C.P.; Reznick, J.B.; Valenzuela, J.E. Variations in Gastric and Duodenal Motility During Gastric Emptying of Liquid Meals in Humans. Gastroenterology 1984, 87, 1114-1119. [CrossRef]

20. Fox, M.; Georgi, G.; Boehm, G.; Menne, D.; Fried, M.; Thumshirn, M. Dietary protein precipitation properties have effects on gastric emptying in healthy volunteers. Clin. Nutr. 2004, 23, 641-646. [CrossRef]

21. Karamanlis, A.; Chaikomin, R.; Doran, S.; Bellon, M.; Bartholomeusz, F.D.; Wishart, J.M.; Jones, K.; Horowitz, M.; Rayner, C.K. Effects of protein on glycemic and incretin responses and gastric emptying after oral glucose in healthy subjects. Am. J. Clin. Nutr. 2007, 86, 1364-1368. [CrossRef]

22. Iba, Y.; Yokoi, K.; Eitoku, I.; Goto, M.; Koizumi, S.; Sugihara, F.; Oyama, H.; Yoshimoto, T. Oral Administration of Collagen Hydrolysates Improves Glucose Tolerance in Normal Mice Through GLP-1-Dependent and GLP-1-Independent Mechanisms. J. Med. Food 2016, 19, 836-843. [CrossRef]

23. Imeryüz, N.; Yegen, B.; Bozkurt, A.; Coşkun, T.; Villanueva-Peñacarrillo, M.L.; Ulusoy, N.B. Glucagon-like peptide-1 inhibits gastric emptying via vagal afferent-mediated central mechanisms. Am. J. Physiol. Liver Physiol. 1997, 273, G920-G927. [CrossRef]

24. Alemán, A.; Giménez, B.; Montero, P.; Gómez-Guillén, M. Antioxidant activity of several marine skin gelatins. LWT 2011, 44, 407-413. [CrossRef]

25. Abdollahi, M.; Rezaei, M.; Jafarpour, A.; Undeland, I. Sequential extraction of gel-forming proteins, collagen and collagen hydrolysate from gutted silver carp (Hypophthalmichthys molitrix), a biorefinery approach. Food Chem. 2018, 242, 568-578. [CrossRef] [PubMed]

26. Iwai, K.; Hasegawa, T.; Taguchi, Y.; Morimatsu, F.; Sato, K.; Nakamura, Y.; Higashi, A.; Kido, Y.; Nakabo, Y.; Ohtsuki, K. Identification of Food-Derived Collagen Peptides in Human Blood after Oral Ingestion of Gelatin Hydrolysates. J. Agric. Food Chem. 2005, 53, 6531-6536. [CrossRef] [PubMed]

27. Meilman, E.; Urivetzky, M.M.; Rapoport, C.M. Urinary Hydroxyproline Peptides. J. Clin. Investig. 1963, 42, 40-50. [CrossRef] [PubMed]

28. Nauck, M.A.; Baller, B.; Meier, J.J. Gastric Inhibitory Polypeptide and Glucagon-Like Peptide-1 in the Pathogenesis of Type 2 Diabetes. Diabetes 2004, 53, S190-S196. [CrossRef] [PubMed]

29. Li, Y.; Aiello, G.; Bollati, C.; Bartolomei, M.; Arnoldi, A.; Lammi, C. Phycobiliproteins from Arthrospira Platensis (Spirulina): A New Source of Peptides with Dipeptidyl Peptidase-IV Inhibitory Activity. Nutrients 2020, 12, 794. [CrossRef]

30. Li-Chan, E.C.; Hunag, S.L.; Jao, C.L.; Ho, K.P.; Hsu, K.C. Peptides derived from Atlantic salmon skin gelatin as dipep-tidylpeptidase IV inhibitors. J. Agric. Food Chem. 2012, 60, 973-978. [CrossRef]

31. Sila, A.; Martinez-Alvarez, O.; Haddar, A.; Gómez-Guillén, M.C.; Nasri, M.; Montero, M.P.; Bougatef, A. Recovery, viscoelastic and functional properties of Barbel skin gelatine: Investigation of anti-DPP-IV and anti-prolyl endopeptidase activities of generated gelatine polypeptides. Food Chem. 2015, 168, 478-486. [CrossRef]

32. Baggio, L.L.; Drucker, D.J. Biology of Incretins: GLP-1 and GIP. Gastroenterology 2007, 132, 2131-2157. [CrossRef]

33. Mortensen, K.; Christensen, L.L.; Holst, J.J.; Orskov, C. GLP-1 and GIP are colocalized in a subset of endocrine cells in the small intestine. Regul. Pept. 2003, 114, 189-196. [CrossRef] 
34. Theodorakis, M.J.; Carlson, O.; Michopoulos, S.; Doyle, M.E.; Juhaszova, M.; Petraki, K.; Egan, J.M. Human duodenal enteroendocrine cells: Source of both incretin peptides, GLP-1 and GIP. Am. J. Physiol. Endocrinol. Metab. 2006, 290, E550-E559. [CrossRef]

35. Hsieh, C.H.; Wang, T.Y.; Hung, C.C.; Chen, M.C.; Hsu, K.C. Improvement of glycemic control in streptozotocin-induced diabetic rats by Atlantic salmon skin gelatin hydrolysate as the dipeptidyl-peptidase IV inhibitor. Food Funct. 2015, 6, 1887-1892. [CrossRef]

36. Harnedy, P.A.; Parthsarathy, V.; McLaughlin, C.M.; O’Keeffe, M.B.; Allsopp, P.J.; McSorley, E.M.; O’Harte, F.P.; FitzGerald, R.J. Atlantic salmon (Salmo salar) co-product-derived protein hydrolysates: A source of antidiabetic peptides. Food Res. Int. 2018, 106, 598-606. [CrossRef] [PubMed]

37. Ohta, T. $\alpha$-Glucosidase inhibitory activity of a 70\% methanol extract from Ezoishige (Pelvetia babingtonii de Toni) and its effect on the elevation of blood glucose level in rats. Biosci. Biotechnol. Biochem. 2002, 66, 1552-1554. [CrossRef] [PubMed] 